\title{
The Daylight Saving Time Anomaly in Stock Returns:
}

\section{Fact or Fiction?}

\author{
Russell Gregory-Allen, \\ Massey University, New Zealand \\ Ben Jacobsen \\ Massey University, New Zealand \\ Wessel Marquering \\ Erasmus University, The Netherlands \\ Taler Asset Management, Gibraltar
}

September 2009

\begin{abstract}
Stock market returns in twenty-two markets around the world show no evidence of a Daylight Saving Time effect. Returns on the days following a switch from or to Daylight Saving Time do not behave any differently from stock market returns on any other day of the week or month. These results reject earlier conclusions in the literature -- based on less data -- that investors' mood changes induced by changes in sleep patterns significantly affect stock returns.
\end{abstract}

Keywords: Daylight Saving Time, International Stock Markets, Behavioral Finance, Anomalies

JEL Classifications: G10, G11, G12, G15 


\section{Introduction}

According to Kamstra, Kramer and Levi (2000), henceforth KKL, investors alter their trading behavior on Mondays after Daylight Saving Time weekends due to changes in their sleep patterns. The empirical evidence of KKL suggests that in the US, UK, Canada and Germany daylight-saving weekends are typically followed by large negative returns in market indices. ${ }^{1}$ Although transactions costs swamp any DST effect, what makes the KKL study interesting is that it adds to the debate in the behavioral finance literature ${ }^{2}$ as to whether external factors, such as weather, sunshine or outcomes of sporting events, can cause investors' mood changes large enough to be observable in stock returns.

We test for the existence of a Daylight Saving Time (DST) anomaly using a larger set of stock markets than KKL in twenty-two countries. This increases over five-fold the number of DST events, which gives us not only a larger sample of countries but also more variety of DST change dates. In these twenty-two stock markets, returns on trading days after weekends with DST changes do not differ from trading days after average weekends. We find a significantly negative DST coefficient only for Luxembourg and only when Luxembourg goes off DST in Fall. For all other countries, our results indicate that trading days after DST changes are nothing special. These results hold when we control for the weekend effect, different months, and the 1987/1997 crashes. If we are as charitable as possible for a DST effect, leaving out a Monday dummy and considering DST on and off switches jointly, we find a significant effect in the UK and at the ten percent level in the US; but, in the other twenty countries there is no significant DST

\footnotetext{
${ }^{1}$ Kamstra, Kramer and Levi (2000) test for the presence of a DST effect in NYSE, AMEX and NASDAQ indices obtained from CRSP and the S\&P500 for the United States, both value and equally weighted. In addition, they use TSE300 for Canada, the UK total market return index and the DAX 100 indices obtained from Datastream. While the US and Canadian indices are probably highly correlated, the advantage of the UK and German results is that they had different DST dates, adding some uncorrelated observations to their sample.

${ }^{2}$ Saunders (1993) and Hirshleifer and Shumway (2003) find a strong relation between cloud cover and stock returns. Kamstra, Kramer and Levi (2003) report evidence of a Seasonal Affective Disorder (SAD) effect in stock returns due to changes in the number of hours of sunlight over a given year. Dichev and Janes (2003) and Yuan, Zheng and Zhu (2006) relate stock returns to lunar phases. More recently, Cao and Wei (2005) link stock market returns to temperature variations.
} 
effect. Apparently, a change in sleeping pattern due to DST does not have a systematic effect on the mood of investors large enough to be discernable in stock returns.

Extending the sample size is important in assessing the existence of a DST effect. Kamstra, Kramer and Levi (2002) point out that their small sample of DST observations may cause some test statistics to show insignificant results, even though point estimates suggest the effect may be present. Extending the data set with many (uncorrelated) observations seems a natural way to help resolve the current debate on the existence of a DST effect in stock returns.

Conclusions regarding the effects of DST changes in other areas also hinge on sample sizes. The basis for the speculation that DST changes affect financial markets is due to similar studies, which examine DST effects on workplace and traffic accidents. For example, Monk (1980), Hicks, Lyndseth and Hawkins (1983) and Coren (1996) find a positive relationship between DST changes and an increase in traffic accidents. But Ferguson (1996) points out that Coren (1996) uses only two years of data, and a more thorough analysis would have found the reverse result. Highlighting the problem of small samples, Coate and Markowitz (2004) examine a different two years from Coren (1996), and do find the opposite -- that DST decreases accidents. Using longer data periods, Ferguson, Preusser, Lund, Zador, and Ulmer (1995) and Sood and Ghosh (2007) show that the level of pedestrian or vehicular accidents over the Spring change is unaffected or actually decreases, due to the hour of extra light. Ferguson, Preusser, Lund, Zador, and Ulmer (1995) and Sullivan and Flannagan (2002), also using an appropriately long data sample, conclude it is the changing ambient light level, rather than the DST change, which has any effect on accidents.

Given that the appropriate data sample can be so important for the conclusions in an arena where one might easily understand the implications, it is much more important to carefully consider the data sample in a study testing the suggestion that sleep desynchronosis will result in financial loss -- a suggestion considerably more controversial than the potential effect of sleep disruption on traffic accidents. 
We are not the first to dispute the claim made by KKL. ${ }^{3}$ Pinegar (2002) finds the KKL results to be driven by two international crises and that the statistical significance of their findings is overstated due to inappropriate use of test statistics. ${ }^{4}$ Lamb, Zuber and Gandar (2004) use the Hadi $(1992,1994)$ outliers test on US data, to determine that the two international crises identified by Pinegar (2002), October 1987 and October 1997, were statistical outliers. Once they remove the outliers, the apparent DST effects vanish. Worthington (2003) highlights the importance of addressing the correct and frequently changing dates for a country where there are multiple, simultaneously applicable standards. After accounting for multiple zones, changing dates, heteroskedasticity and autocorrelation, he finds no DST effect in Australia.

In a reply to Pinegar (2002), Kamstra, Kramer and Levi (2002) take issue with Pinegar's statistical arguments, but also re-emphasize a point made in KKL, that the economic significance of a large market such as the US reacting to a DST event, in and of itself, makes the event worthy of notice. However, it is possible that the noted US effect is a statistical artifact and therefore the economic significance is spurious. To help control for that possibility, KKL add three other countries, Canada, UK and Germany.

\footnotetext{
${ }^{3}$ There are many studies which re-examine other claims made in this strand of the literature. Kelly and Meschke (2007) offer theoretical and empirical evidence against SAD causing an effect in stock returns as documented by Kamstra, Kramer and Levi (2003). Jacobsen and Marquering (2008) show that Kamstra, Kramer and Levi (2003) and Cao and Wei (2005) measure a similar effect as already reported by Jacobsen and Bouman (2002). Further, as many things tend to be correlated with the seasons, claims that it is SAD or temperature causing a seasonal effect are based on the empirical evidence they report, and are premature. That data-driven inference based on spurious correlations might also be a problem for the studies using cloud cover is illustrated in the recent work of Goetzmann and Zhu (2002). They find a strong correlation between stock returns and cloud cover. However, when they consider the trading accounts of individual investors, they find no evidence that their trading behavior is influenced by the degree of cloud cover.

${ }^{4}$ To be more precise: KKL find significantly lower DST returns in the United States, Canada and the UK but not in Germany. Their t-statistics are in most cases well below -2. For Germany they find a t-statistic of -0.33 . They attribute the latter finding to a lack of data. As daily data in particular are extremely heteroskedastic, using t-statistics assuming normality as KKL do, will too frequently reject the null hypothesis of no DST effect. While Pinegar (2002) is able to reproduce the KKL results using t-statistics based on normality, he finds no significant results using t-statistics properly adjusted using heteroskedasticity consistent standard errors for the US. In that case, t-values range between -1.27 and 1.74 .
} 
Unfortunately, the Canadian stock market has a high correlation with the US ( $\rho=0.66$ over KKL's time period for the data series we use). To make matters worse, once Canada began observing DST, their DST date changes have been identical to those of the US. Therefore, the addition of Canada is not of much help with statistical robustness. Between the UK and Germany, the correlation is not as high ( $\rho=0.43$ over the KKL period), and while the DST changes are not all the same as the US/Canada, most of these two countries' Spring changes have been at the same time, even prior to 1996 when most countries began changing together. ${ }^{5}$

In order to distinguish between spurious economic significance and true statistical significance, the obvious solution is to use a larger data sample -- more countries, over more years, with diverse dates. KKL state:

Furthermore, if the daylight-saving effect was spurious in the North American data, we would be unlikely to find a similar pattern in a country that observes daylight saving on other dates altogether. ${ }^{6}$

We agree, but a priori, there is no clear reason why one should restrict attention to only four countries -- especially countries that are likely to have similar results. In cases like this, where there is no reason to expect investors across countries to act fundamentally differently, using a large number of countries is a useful approach to avoid inferences based on spurious results. We examine twenty-two countries over about a one-third longer time span; this results in about 1,150 DST events, as opposed to KKL's approximately 200. While the economic size of these markets varies considerably, what matters is having more data series, with different DST dates. This much larger sample will help to ensure statistically sound results.

\footnotetext{
${ }^{5}$ As noted in footnote 1, KKL include five indices for the US. Beyond a stated desire to capture a DST size effect, their reasoning remains unclear. All these indices are very highly correlated, and obviously the DST change dates are identical.

${ }^{6}$ KKL, p. 1007.
} 


\section{Data}

\section{A. Stock market data}

We use daily stock returns of value-weighted indices for twenty-two of the countries which made up the MSCI World Index during most of our sample period: Australia, Austria, Belgium, Canada, Denmark, Finland, France, Germany, Greece, Hong Kong, Ireland, Italy, Luxembourg, the Netherlands, Norway, New Zealand, Portugal, Spain, Sweden, Switzerland, the United Kingdom, and the United States. ${ }^{7}$ Data are from Global Financial Data (GFD), all in home currency, and all local holidays assigned missing returns (unlike Datastream, GFD does not "fill in" missing data). For most countries, GFD has multiple composite indices. In each case, we choose the most broad and comprehensive index available. For every country we have long daily data series available, and all these countries have DST changes over a large part of our sample. All series end in December 2005. Table I contains summary statistics for all indices.

\section{Please insert Table I around here.}

It is well known that daily stock returns show high kurtosis. Our data are no different; we find for all series extremely high estimates for kurtosis. As pointed out by Pinegar (2002), this invalidates the use of test statistics based on normality as done by KKL. They use normal standard errors rather than commonly-used corrections such as White or NeweyWest standard errors. Daily data are well-known to be heteroscedastic and as these traditional standard errors may overstate significance, we use White (1980) standard errors in our regressions. ${ }^{8}$

\footnotetext{
${ }^{7}$ We omit Japan and Singapore, as neither country has observed DST, except temporarily during World War II (during which we have no returns data). Luxembourg is no longer part of the MSCI index.

${ }^{8}$ We also examined KKL's dates and time periods with and without error correction. Before correction, we find the results they do. After employing White standard errors, the significant effects nearly disappear. See Appendix 1 for details.
} 


\section{B. DST changes}

From the first inspiration in 1784 by Benjamin Franklin, DST has been controversial. Opponents have been primarily either those whose schedules were tied to the sun (such as farmers) or those who would not benefit from its usage (e.g., those living in midlatitudes). As a result, acceptance of DST was slow and progressed inconsistently. Often when one region enacted DST, a neighboring region would reject it. It was nearly 200 years before national standards began to appear. ${ }^{9}$ Italy introduced a national DST standard in May, 1966. ${ }^{10}$ The USA followed in 1967, Hong Kong in 1969, and the UK and Australia in 1971. From the mid-to-late 1970s, other countries began enacting national DST standards until 1980, at which time most of continental Europe agreed to go on and off DST, respectively, on the first Sunday in April and the last Sunday in September. ${ }^{11}$ Over the next two years, Sweden and Switzerland joined, and there were a few refinements and modifications over the next decade or so, with each change moving closer to the near standardization we now have.

\section{DST Date Selection}

For each country, we record the exact date that each DST change occurs (after national standardization) during the period for which we have stock index daily returns.

Thus, in the UK, for example, although there have been regular DST events since 1916, they stayed "on" DST from February 18, 1968 until Fall 1971. Our UK stock index returns data begins in January 1969; so, our first DST event for the UK is their Fall change on October 31, 1971.

\footnotetext{
${ }^{9}$ See Prerau (2005).

${ }^{10}$ Prior to national standards, DST policies often varied from one region to the next. Since this would dissipate any generalized DST effect, for each country we begin the data series with the national standardization (or the first return, whichever is later).

${ }^{11}$ All of these dates are from Shanks and Pottenger (2003).
} 
France is typical of the Euro countries. DST events began in 1916 and were fairly consistent through World War II. At the close of the war, France went off DST and did not resume until Spring 1976. Our French returns data begin September 1968, so our first DST event for France is the Spring DST change on March 28, 1976. Other countries vary considerably as to when they resumed after WWII (e.g., 1966 for Italy, 1981 for Switzerland), but they all follow the same pattern.

There are four countries that present a challenge when defining DST dates: Australia, Canada, UK and USA. For each of these, over the years and even now, there have been multiple, simultaneous DST standards. In order to minimize the dissipation of any DST effect that multiple standards would cause, we begin our data for any given country when the DST standard became nationalized or widespread. In Australia and Canada, there are still large areas that use different standards, so we use the DST standard in the city of the primary stock exchange: Sydney for Australia and Toronto for Canada. In both countries, this is also the standard that represents the majority of the country.

In the UK, nationalization occurred at about the same time as our returns data begin. However, in the USA we have returns data from 1928, but standards were not nationalized until 1967. Our first DST standardized event for the US is therefore April 30, $1967 .{ }^{12}$ In both countries, there are some regional exceptions to the national standard, but the standard for the primary stock exchange city (London for UK and New York for USA) also represents the majority of the country.

For all twenty-two countries, even after a standard was in place, there were modifications -- sometimes temporary and sometimes permanent. For example, when standards in the USA were nationalized in 1967, DST began on the fourth Sunday in April. However, in response to the 1973 Oil Crisis, in 1974 DST began on the first Sunday in January; in 1975 it changed to the last Sunday in February; and then in 1976 it returned to the last Sunday in April. Finally, in 1987 it changed "permanently" to the first Sunday in April.

\footnotetext{
${ }^{12}$ There was one national DST event shortly after the close of WWII; on September 30, 1945, DST was repealed and not resumed nationally until standardization began in 1967.
} 
There have been similar refinements and/or temporary changes in all of our twenty-two countries (Shanks and Pottenger, 2003; Prerau, 2005). For each country, we record the exact date of each DST change rather than follow something like a simple "1st Sunday" algorithm. $^{13}$

\section{Current Standards}

As of the end of our sample period in 2005, most northern-hemisphere MSCI countries go on and Australia goes off DST on the last Sunday in March; US and Canada go on one week later (on the first Sunday in April), while New Zealand goes off one week earlier (on the 3rd Sunday in March). In October, all countries except New Zealand change on the last Sunday, and New Zealand goes on DST on the first Sunday.

For each country, we use dates of DST changes from Shanks and Pottenger (2003), noting when each actually occurred. ${ }^{14}$ In Table I we report the start of DST changes for every country in our sample.

\section{Methodology and Results}

To test for the existence of a DST effect, ${ }^{15}$ we use regressions of the form:

$$
r_{t}=\mu+\alpha_{1} D S T_{t}^{\text {spring }}+\alpha_{2} D S T_{t}^{\text {fall }}+\alpha_{3} \text { Monday } y_{t}+\varepsilon_{t}
$$

\footnotetext{
${ }^{13}$ We present a complete list of DST dates in Appendix 2.

${ }^{14}$ Some of our dates differ from KKL. After date correction and at a 5\% level, significant effects vanish (see Appendix 1 for details).

${ }^{15}$ Ideally, we would test the Spring and Fall DST dates for countries that follow DST against a control sample of countries that do not. However, that would require that all countries have DST changes at the same time; unfortunately, it has only been in the last decade that most countries change at the same time, and even now both Spring and Fall DST changes are not unique across countries. In this case we must treat each DST event for each country as a separate event.
} 
where the DST dummy takes the value 1 on the Monday after there has been a DST change. ${ }^{16}$ To separate a possible weekend effect from a DST effect, we include a Monday dummy. Moreover, in order to give the DST effect the benefit of the doubt, we do not adjust for the large events in our sample that coincide with the DST changes as noted by Pinegar (2002).

The first question we address is whether stock returns after DST changes are different from returns on normal trading days. We test this hypothesis using the regression equation above. In the robustness checks below, we consider several variations of this equation.

\section{Please insert Table II around here.}

We report the results in Table II. In line with the literature, the Monday dummy in our analysis is frequently negative and significantly so. With respect to the daylight saving time coefficients, we find a significant DST Fall effect for Luxembourg only. While we find negative effects for Canada, the UK and the US, these are not significant. For Germany, we observe an insignificant positive Spring effect. For the remaining eighteen countries, we find no indication of significant DST effects, except for a positive significant Fall effect in Hong Kong at the ten percent level. Considering that when based on usual confidence levels, one might find spurious significant results in five or ten percent of the sample, in our study these significant results for Luxembourg (negative) and Hong Kong (positive) seem attributable to mere chance. The absence of a clear pattern in the signs of the DST coefficients confirms that conclusion.

\footnotetext{
${ }^{16}$ There were no instances where a holiday followed a DST change. There were a few instances when the DST change did not occur on a Sunday. All but two occurred prior to the first return in our data sample. For the USA, there were two changes (on a Monday and a Tuesday) around World War II; we drop these as being different events and so not comparable (a Sunday change to a Monday return is a 1-day physiological event; a Monday change to a Monday return is a 0 -day event).
} 


\section{A. Robustness Checks}

Few control variables are likely to show strong correlations with the DST variables; in our analysis we can treat most potential control variables as white noise with respect to the DST variables. Moreover, we use heteroskedastic consistent standard errors, which assures robustness against more specific models of heteroskedasticity such as ARCH and GARCH models. However, there are a number of checks we need to perform.

Our first check is to see what happens if we leave out the Monday dummy and test the significance of both DST coefficients jointly. Even though this biases our test in favor of a DST effect, we only find a significant effect for the UK and at the ten percent level for the US (consistent with KKL). For both countries, the DST Fall switch drives the result. ${ }^{17}$ In all other countries, DST coefficients remain insignificant. Contrary to what one would expect if there were a DST effect, many countries show mean positive returns after DST changes, both in the joint estimation and for the separated Spring and Fall effects. If we estimate all country equations jointly using GMM and White's heteroskedasticity consistent covariance matrix, we also reject the joint hypothesis that the dummy coefficients are significantly different from zero ( $p$-value $=0.11$ ). Even if give the DST effect the benefit of the doubt, our data do not support the existence of a DST effect in stock market returns.

Pinegar (2002) and Lamb, Zuber and Gandar (2004) note that eliminating October 1987 and October 1997 from the US data causes the DST effect to vanish. Kamstra, Kramer and Levi (2002) suggest that the crashes are exactly what one might expect from desynchronosis. However, in Kamstra, Kramer and Levi (2000) they also suggest (as noted earlier) that any real phenomenon should show up in other countries as well. We apply a crash dummy to our previous regressions across all countries (see Table III), confirming the results of Pinegar (2002) and Lamb, Zuber and Gandar (2004). All

\footnotetext{
${ }^{17} \mathrm{We}$ do not report these results in a separate table but they are available on request from the authors.
} 
countries, of course, have a significantly negative coefficient for the crashes; however, for the non-crash DST events, the DST effect is essentially non-existent ${ }^{18}$.

\section{Please insert Table III around here.}

There is some evidence in the literature suggesting that there is a variation in stock returns across different months, and most DST changes occur in April and October. To control for any month effect, we include a dummy variable for the months in which we observe DST changes. These results, reported in Table IV, show that our original results are hardly affected.

Please insert Table IV around here.

\section{Summary and Conclusion}

Kamstra, Kramer and Levi (2000) find that sleep desynchronosis from daylight saving time changes results in an observable negative impact on stock returns. Several authors have questioned this result, focusing on KKL's statistical technique and the effect of outliers. Though these studies cast doubt on the validity of KKL's results, they were all subject to the same limited data samples, and there was still the possibility that KKL's findings were due to a real physiological and economic event, rather than a spurious statistical artifact.

We extend the work of previous authors, primarily by examining twenty-two countries instead of four, but also by looking at a longer time span. This provides us with more than five times as many observations as KKL, and gives us more varied "event dates". That, along with proper standard error corrections and several robustness checks, ensures that our results are a more conclusive answer to the question of whether the DST effect is real

\footnotetext{
${ }^{18}$ Austria has a significant positive Fall coefficient, but as this is 1 result out of 44, at conventional confidence levels, this does not indicate a significant effect.
} 
or spurious. We find no evidence of an observable DST effect in stock returns. Our results reject earlier conclusions that investors' mood changes induced by changes in sleep patterns due to daylight-saving time significantly affect stock returns. 


\section{References}

Bouman, Sven and Ben Jacobsen, 2002, "The Halloween Indicator, Sell in May and Go Away: Another Puzzle", American Economic Review, 92(5), 1618-1635.

Cao, Melanie and Jason Wei, 2005, "Stock Market Returns: A Temperature Anomaly", Journal of Banking and Finance, 29, 1559-1573.

Coate, Douglas and Sara Markowitz, 2004, "The Effects of Daylight and Daylight Saving Time on US Pedestrian Fatalities and Motor Vehicle Occupant Fatalities", Accident Analysis \& Prevention, 36(3), 351-357.

Coren, Stanley, 1996, "Daylight Savings Time and Traffic Accidents", The New England Journal of Medicine, 334(14), 924.

Dichev, Ilia D. and Troy. D. Janes, 2003, "Lunar Cycle Effects in Stock Returns", Journal of Private Equity, 6(4), 8-29.

Ferguson, Susan A., 1996, "Traffic Accidents and Daylight Saving Time", The New England Journal of Medicine, 335(5), 335-357.

Ferguson, Susan A., David. F. Preusser, Adrian. K. Lund, Paul. L. Zador, and Robert. G. Ulmer, 1995, "Daylight Saving Time and Motor Vehicle Crashes: the Reduction in Pedestrian and Vehicle Occupant Fatalities", American Journal of Public Health, 85(1), 92-95.

Gerbi, S.A., M.A. MacKintosh, and R.A. Hicks, 1996, "Alterations in Sleep Patterns, Tiredness, and Fatigue after the Spring Daylight Saving Time Change", Sleep Research, 25, 550 .

Goetzmann, William N. and Ning Zhu, 2002, "Rain or Shine: Where is the Weather Effect?”, European Financial Management, 11(5), 559-578.

Hadi, Ali S., 1992, "Identifying Multiple Outliers in Multivariate Data", Journal of the Royal Statistical Society, Series B, 54, 761-771.

Hadi, Ali S., 1994, "A Modification of a Method for the Detection of Outliers in Multivariate samples", Journal of the Royal Statistical Society, Series B, 56, 393 396.

Hicks, Robert A., Kristin Lyndseth and James Hawkins, 1983, "Daylight-Saving Time Changes Increase Traffic Accidents", Perceptual and Motor Skills, 56(1), 64-66.

Hirshleifer, David and Tyler Shumway, 2003, "Good Day Sunshine: Stock Returns and the Weather", Journal of Finance, 58(3), 1009-1032.

Jacobsen, Ben and Wessel Marquering, 2008, "Is it the Weather?", Journal of Banking and Finance, 32(4),526-540.

Kamstra, Mark J., Lisa A. Kramer and Maurice D. Levi, 2000, "Losing Sleep at the Market: The Daylight Savings Anomaly", American Economic Review, 90(4), 1005-1011.

Kamstra, Mark J., Lisa A. Kramer and Maurice D. Levi, 2002, "Losing Sleep at the Market: Reply", American Economic Review, 92(4), 1257-1263. 
Kamstra, Mark J., Lisa A. Kramer and Maurice D. Levi, 2003, "Winter Blues: A SAD Stock Market Cycle”, American Economic Review, 93(1), 324-343.

Kelly, Patrick J. and J. Felix Meschke, 2004, "Sentiment and Stock Returns: The SAD Anomaly Revisited", Working Paper, University of South Florida.

Lamb, Reinhold, Richard Zuber and John Gandar, 2004, "Don't Lose Sleep on it: a Reexamination of the Daylight Savings Time Anomaly", Applied Financial Economics, 14, 443-446.

Monk, Timothy H., 1980, "Traffic Accident Increases as a Possible Indicant of Desynchronsis", Cronobiologica, 7(4), 527-529.

Newey, Whitney and Kenneth West, 1987, "A Simple, Positive Semi-definite, Heteroskedasticity and Autocorrelation Consistent Covariance Matrix", Econometrica, 55(3), 703-708.

Pinegar, Michael, 2002, "Losing Sleep at the Market: Comment", American Economic Review, 92(4), 1251-1256.

Prerau, David, 2005, "Seize the Daylight - The Curious and Contentious Story of Daylight Saving Time", Thunder's Mouth Press, New York.

Saunders, Edward M., 1993, "Stock Prices and Wall Street Weather", American Economic Review, 83(5), 1337-1345.

Shanks, Thomas G., 1985, "The International Atlas", ACS Publications.

Shanks, Thomas G. and Rique Pottenger, 2003, “The International Atlas Expanded, Sixth Edition", ACS Publications.

Sood, Neeraj, and Arkadipta Ghosh, 2007, "The Short and Long Run Effects of Daylight Saving Time on Fatal Automobile Crashes", B.E. Journal of Economic Analysis \& Policy, 7(1), Article 11.

Sullivan, John M. and Michael J. Flannagan, 2002, “The Role of Ambient Light Level in Fatal Crashes: Inferences from Daylight Saving Time Transitions", Accident Analysis and Prevention, 34(4), 487-498.

White, Halbert, 1980, "A Heteroskedasticity-Consistent Covariance Matrix Estimator and a Direct Test for Heteroskedasticity," Econometrica, 48, 817-838.

Worthington, Andrew, 2003, "Losing Sleep at the Market: An Empirical Note on the Daylight Saving Anomaly in Australia”, Working Paper, Queensland University of Technology.

Yuan, Kathy, Lu Zheng and Qiaoqiao Zhu, 2006, “Are Investors Moonstruck? - Lunar Phases and Stock Returns", Journal of Empirical Finance, 13(1), 1-23 
Table I. Summary results on value-weighted MSCI re-investment indices

This table gives descriptive statistics for daily index returns for twenty-two countries. The starting date for each country is given in the third column, and the ending date for all series is 12/30/2005. All indices are value-weighted, in domestic currency, including dividend distributions. Std. Dev. denotes standard deviation. The mean, standard deviation, maximum and minimum are all in percentages. $\mathrm{N}$ represents the number of observations in the sample for the corresponding country.

\section{Country* $\quad$ Starting date 1 st DST date Mean $\quad$ Std. Dev. Skewness Kurtosis N of returns in our sample**}

\begin{tabular}{llllllll}
\hline Australia (Sydney) & 07-Jan-58 & 31-Oct-71 & 0.029 & 0.842 & -3.707 & 124.373 & 11982 \\
Austria & 08-Jan-62 & 06-Apr-80 & 0.015 & 0.692 & -0.329 & 21.706 & 10783 \\
Belgium & 03-Jan-85 & 31-Mar-85 & 0.035 & 0.903 & -0.220 & 15.773 & 5141 \\
Canada (Toronto) & 05-Jan-76 & 25-Apr-76 & 0.032 & 0.843 & -0.968 & 17.155 & 7479 \\
Denmark & 18-Jan-79 & 06-Apr-80 & 0.043 & 0.829 & -0.528 & 8.772 & 6645 \\
Finland & 05-Jan-87 & 29-Mar-87 & 0.042 & 1.735 & -0.439 & 11.641 & 4674 \\
France & 18-Sep-68 & 28-Mar-76 & 0.032 & 1.057 & -0.568 & 11.942 & 9151 \\
Germany & 05-Jan-70 & 06-Apr-80 & 0.025 & 1.118 & -0.376 & 12.981 & 12248 \\
Greece & 03-Aug-89 & 24-Sep-89 & 0.057 & 1.725 & 0.103 & 8.362 & 4223 \\
Hong Kong & 25-Nov-69 & 19-Apr-70*** & 0.051 & 1.909 & -1.378 & 35.441 & 8822 \\
Ireland & 05-Jan-87 & 29-Mar-87 & 0.039 & 1.048 & -0.959 & 15.299 & 4649 \\
Italy & 14-Dec-56 & 22-May-66 & 0.025 & 1.234 & -0.378 & 9.538 & 11986 \\
Luxembourg & 03-Jan-85 & 31-Mar-85 & 0.045 & 0.892 & -0.381 & 17.280 & 5189 \\
Netherlands & 03-Jan-80 & 06-Apr-80 & 0.036 & 1.157 & -0.336 & 10.589 & 6506 \\
New Zealand & 06-Jan-70 & 03-Nov-74 & 0.024 & 0.856 & -1.216 & 26.845 & 8870 \\
Norway & 04-Jan-83 & 27-Mar-83 & 0.057 & 1.179 & -1.433 & 28.564 & 5686 \\
Portugal & 03-Jan-86 & 30-Mar-86 & 0.044 & 1.131 & -0.773 & 30.322 & 4656 \\
Spain & 13-Sep-71 & 13-Apr-74 & 0.033 & 1.096 & -0.203 & 8.406 & 7751 \\
Sweden & 03-Jan-80 & 06-Apr-80 & 0.059 & 1.215 & -0.202 & 8.870 & 6410 \\
Switzerland & 06-Jan-69 & 29-Mar-81 & 0.020 & 0.931 & -0.852 & 13.955 & 9160 \\
UK (London) & 02-Jan-69 & 31-Oct-71 & 0.029 & 1.021 & -0.298 & 11.103 & 9276 \\
US (New York) & 04-Jan-28 & 30-Apr-67 & 0.021 & 1.167 & -0.469 & 23.356 & 19583 \\
\hline
\end{tabular}

* For most countries, DST is standard throughout, but four countries have multiple standards. In each of those, we use the DST dates for the city where the primary stock exchange is located, which also happens to represent the majority DST standard of the country.

** Many countries had some DST changes prior to this date; we begin where we have returns data (see Appendix 2 for date details).

*** Hong Kong DST ends Oct 19, 1980; for all other countries DST goes through Fall 2005. 
Table II. Regression of index returns on a Monday dummy and two daylight saving time dummies: one hour increase or decrease

This table reports coefficient estimates from running twenty-two country regressions of index returns on a constant, a Monday dummy, and two dummies for the Monday following a daylight saving time change: one dummy for an hour increase and one for an hour decrease (DST Spring or Fall). All indices are value-weighted, in domestic currency, including dividend distributions. We present parameter estimates (in percentages) with associated t-statistics in parentheses below, calculated using White's (1980) heteroskedasticity-robust standard errors. An asterisk denotes significance at the 5 percent level. For each regression, we report in the last column the $\chi 2$ realization and p-value in square brackets for a $\chi 2$ test whether DST days (Spring and Fall) are different from all other trading days.

\begin{tabular}{|c|c|c|c|c|c|}
\hline \multirow{2}{*}{ Country } & \multirow[b]{2}{*}{ Const. } & \multicolumn{2}{|c|}{ DST change } & \multirow[b]{2}{*}{ Monday } & \multirow{2}{*}{$\begin{array}{c}\text { Chi-Sq } \\
\text { [p-value] }\end{array}$} \\
\hline & & Spring & Fall & & \\
\hline \multirow[t]{2}{*}{ Australia } & $0.037^{*}$ & -0.207 & 0.112 & $-0.041^{*}$ & 1.326 \\
\hline & $(4.45)$ & $(-0.84)$ & $(0.68)$ & $(-1.96)$ & {$[0.52]$} \\
\hline \multirow[t]{2}{*}{ Austria } & $0.012^{*}$ & -0.018 & 0.325 & 0.010 & 2.159 \\
\hline & $(1.77)$ & $(-0.15)$ & $(1.50)$ & $(0.54)$ & {$[0.34]$} \\
\hline \multirow[t]{2}{*}{ Belgium } & $0.045^{*}$ & -0.225 & 0.003 & -0.048 & 0.498 \\
\hline & (3.38) & $(-0.82)$ & $(0.02)$ & $(-1.34)$ & {$[0.78]$} \\
\hline \multirow[t]{2}{*}{ Canada } & $0.047^{*}$ & -0.040 & -0.325 & $-0.073^{*}$ & 0.546 \\
\hline & $(4.51)$ & $(-0.31)$ & $(-0.89)$ & $(-2.78)$ & {$[0.76]$} \\
\hline \multirow[t]{2}{*}{ Denmark } & $0.056^{*}$ & 0.261 & 0.119 & $-0.072^{*}$ & 3.551 \\
\hline & $(5.05)$ & $(1.40)$ & $(0.51)$ & $(-2.71)$ & {$[0.17]$} \\
\hline \multirow[t]{2}{*}{ Finland } & 0.045 & -0.282 & -0.282 & -0.007 & 0.730 \\
\hline & $(1.58)$ & $(-0.68)$ & $(-0.61)$ & $(-0.12)$ & {$[0.69]$} \\
\hline \multirow[t]{2}{*}{ France } & $0.039^{*}$ & 0.225 & -0.049 & -0.042 & 0.915 \\
\hline & $(3.27)$ & $(0.82)$ & $(-0.21)$ & $(-1.43)$ & {$[0.63]$} \\
\hline \multirow[t]{2}{*}{ Germany } & $0.032^{*}$ & -0.129 & 0.190 & -0.038 & 0.430 \\
\hline & $(3.04)$ & $(-0.44)$ & $(0.48)$ & $(-1.34)$ & {$[0.81]$} \\
\hline \multirow[t]{2}{*}{ Greece } & $0.082^{*}$ & -0.338 & -0.113 & -0.118 & 0.307 \\
\hline & (3.01) & $(-0.90)$ & $(-0.20)$ & $(-1.43)$ & {$[0.86]$} \\
\hline \multirow[t]{2}{*}{ Hong Kong } & $0.088^{*}$ & -0.150 & 1.092 & $-0.201^{*}$ & 3.696 \\
\hline & $(4.31)$ & $(-0.25)$ & $(1.64)$ & $(-3.11)$ & {$[0.16]$} \\
\hline \multirow[t]{2}{*}{ Ireland } & $0.046^{*}$ & -0.230 & -0.753 & -0.017 & 2.185 \\
\hline & $(2.79)$ & $(-0.81)$ & $(-1.37)$ & $(-0.42)$ & {$[0.34]$} \\
\hline \multirow[t]{2}{*}{ Italy } & $0.050^{*}$ & 0.018 & 0.148 & $-0.128^{*}$ & 2.030 \\
\hline & $(4.18)$ & $(0.08)$ & $(0.72)$ & $(-4.01)$ & {$[0.36]$} \\
\hline \multirow[t]{2}{*}{ Luxembourg } & $0.046^{*}$ & 0.037 & $-0.291^{*}$ & 0.002 & 3.900 \\
\hline & $(3.38)$ & $(0.22)$ & $(-2.03)$ & $(0.06)$ & {$[0.14]$} \\
\hline \multirow[t]{2}{*}{ Netherlands } & $0.050^{*}$ & -0.320 & -0.252 & -0.060 & 1.035 \\
\hline & $(3.27)$ & $(-0.95)$ & $(-0.98)$ & $(-1.47)$ & {$[0.60]$} \\
\hline \multirow[t]{2}{*}{ New Zealand } & $0.031^{*}$ & -0.337 & -0.089 & -0.027 & 0.937 \\
\hline & $(3.10)$ & $(-1.01)$ & $(-0.60)$ & $(-1.09)$ & [0.63] \\
\hline \multirow[t]{2}{*}{ Norway } & $0.072^{*}$ & 0.014 & 0.019 & $-0.073^{*}$ & 0.257 \\
\hline & $(4.24)$ & $(0.06)$ & $(0.08)$ & $(-1.70)$ & {$[0.88]$} \\
\hline \multirow[t]{2}{*}{ Portugal } & $0.057^{*}$ & -0.076 & 0.201 & $-0.082^{*}$ & 1.212 \\
\hline & $(3.07)$ & $(-0.43)$ & $(0.81)$ & $(-2.14)$ & {$[0.55]$} \\
\hline \multirow[t]{2}{*}{ Spain } & $0.021^{*}$ & -0.048 & -0.121 & $0.096^{*}$ & 1.048 \\
\hline & $(1.67)$ & $(-0.25)$ & $(-0.44)$ & $(2.17)$ & {$[0.59]$} \\
\hline Sweden & $0.067^{*}$ & -0.241 & -0.229 & -0.030 & 0.731 \\
\hline & $(4.09)$ & $(-0.81)$ & $(-0.63)$ & $(-0.73)$ & {$[0.69]$} \\
\hline Switzerland & $0.039^{*}$ & -0.164 & -0.004 & $-0.093^{*}$ & 0.185 \\
\hline & $(3.75)$ & $(-0.56)$ & $(-0.02)$ & $(-3.42)$ & {$[0.91]$} \\
\hline UK & $0.050^{*}$ & -0.217 & -0.325 & $-0.100^{*}$ & 0.958 \\
\hline & $(4.37)$ & $(-1.12)$ & $(-1.19)$ & $(-3.48)$ & {$[0.62]$} \\
\hline US & $0.055^{*}$ & -0.013 & -0.382 & $-0.121^{*}$ & 1.349 \\
\hline & (7.36) & $(-0.10)$ & $(-1.25)$ & $(-5.90)$ & {$[0.51]$} \\
\hline
\end{tabular}


Table III. Regression of index returns on a on a crash dummy, Monday dummy and two daylight saving time dummies: one hour increase or decrease

This table reports coefficient estimates from running twenty-two country regressions of index returns on a constant, a "Market Crash" dummy (corresponding to the October stock market crashes in 1987 and 1997), a Monday dummy, and two dummies for the Monday following a daylight saving time change: one dummy for an hour increase and one for an hour decrease (DST Spring or Fall). All indices are value-weighted, in domestic currency, including dividend distributions. We present parameter estimates (in percentages) with associated t-statistics in parentheses below, calculated using White's (1980) heteroskedasticity-robust standard errors. An asterisk denotes significance at the 5 percent level. For each regression, we report in the last column the $\chi^{2}$ realization and p-value in square brackets for a $\chi^{2}$ test whether DST days (Spring and Fall) are different from all other trading days.

\begin{tabular}{|c|c|c|c|c|c|c|}
\hline \multirow[b]{2}{*}{ Country } & \multirow[b]{2}{*}{ Const. } & \multicolumn{2}{|c|}{ DST change } & \multirow[b]{2}{*}{ Monday } & \multirow[b]{2}{*}{ Crash } & \multirow{2}{*}{$\begin{array}{r}\text { Chi-Sq } \\
\text { [p-value }\end{array}$} \\
\hline & & Spring & Fall & & & \\
\hline \multirow[t]{2}{*}{ Australia } & $0.037^{*}$ & 0.093 & 0.110 & $-0.039^{*}$ & $-5.155^{*}$ & 1.024 \\
\hline & $(4.45)$ & $(0.77)$ & $(0.67)$ & $(-1.86)$ & $(-4.23)$ & {$[0.60]$} \\
\hline \multirow[t]{2}{*}{ Austria } & $0.013^{*}$ & -0.021 & $0.428^{*}$ & 0.013 & $-2.606^{*}$ & 4.640 \\
\hline & $(1.83)$ & $(-0.17)$ & $(2.14)$ & $(0.66)$ & $(-13.11)$ & {$[0.10]$} \\
\hline \multirow[t]{2}{*}{ Belgium } & $0.046^{*}$ & -0.230 & 0.173 & -0.039 & $-3.544^{*}$ & 2.069 \\
\hline & $(3.36)$ & $(-0.84)$ & $(1.15)$ & $(-1.13)$ & $(-5.20)$ & {$[0.36]$} \\
\hline \multirow[t]{2}{*}{ Canada } & $0.047^{*}$ & -0.046 & 0.170 & $-0.068^{*}$ & $-7.268^{*}$ & 1.763 \\
\hline & $(4.49)$ & $(-0.35)$ & $(1.27)$ & $(-2.57)$ & $(-13.37)$ & {$[0.41]$} \\
\hline \multirow[t]{2}{*}{ Denmark } & $0.056^{*}$ & 0.256 & 0.169 & $-0.065^{\star}$ & $-1.411^{*}$ & 2.390 \\
\hline & $(5.05)$ & $(1.37)$ & $(0.74)$ & $(-2.44)$ & $(-8.87)$ & {$[0.30]$} \\
\hline \multirow[t]{2}{*}{ Finland } & 0.045 & -0.290 & -0.088 & 0.005 & $-3.697^{*}$ & 0.549 \\
\hline & $(1.57)$ & $(-0.70)$ & $(-0.25)$ & $(0.08)$ & $(-2.47)$ & {$[0.76]$} \\
\hline \multirow[t]{2}{*}{ France } & $0.040^{*}$ & 0.220 & 0.149 & -0.035 & $-5.971^{*}$ & 1.019 \\
\hline & $(3.29)$ & $(0.79)$ & $(0.63)$ & $(-1.19)$ & $(-2.61)$ & {$[0.60]$} \\
\hline \multirow[t]{2}{*}{ Germany } & $0.033^{*}$ & -0.133 & 0.380 & -0.035 & $-4.841^{*}$ & 1.213 \\
\hline & $(3.10)$ & $(-0.45)$ & $(1.00)$ & $(-1.23)$ & $(-5.83)$ & {$[0.55]$} \\
\hline \multirow[t]{2}{*}{ Greece } & $0.080^{*}$ & -0.341 & 0.048 & -0.113 & $-2.627^{*}$ & 0.834 \\
\hline & $(2.96)$ & $(-0.91)$ & $(0.08)$ & $(-1.39)$ & $(-4.60)$ & {$[0.66]$} \\
\hline \multirow[t]{2}{*}{ Hong Kong } & $0.089^{*}$ & -0.172 & 1.062 & $-0.170^{*}$ & $-23.176^{*}$ & 2.650 \\
\hline & $(4.35)$ & $(-0.29)$ & $(1.60)$ & $(-2.87)$ & $(-1.90)$ & {$[0.27]$} \\
\hline \multirow[t]{2}{*}{ Ireland } & $0.045^{*}$ & -0.235 & -0.756 & -0.010 & $-3.500^{*}$ & 2.531 \\
\hline & $(2.75)$ & $(-0.82)$ & $(-1.37)$ & $(-0.23)$ & $(-8.20)$ & {$[0.28]$} \\
\hline \multirow[t]{2}{*}{ Italy } & $0.051^{*}$ & 0.012 & 0.257 & $-0.123^{*}$ & $-4.067^{*}$ & 1.950 \\
\hline & $(4.30)$ & $(0.06)$ & $(1.39)$ & $(-3.84)$ & $(-8.49)$ & {$[0.38]$} \\
\hline \multirow[t]{2}{*}{ Luxembourg } & $0.046^{*}$ & -0.025 & -0.260 & 0.010 & $-0.590^{*}$ & 0.315 \\
\hline & $(3.40)$ & $(-0.19)$ & $(-1.52)$ & $(0.31)$ & $(-4.47)$ & {$[0.31]$} \\
\hline \multirow[t]{2}{*}{ Netherlands } & $0.048^{*}$ & -0.329 & -0.043 & -0.046 & $-5.530^{*}$ & 0.978 \\
\hline & $(3.17)$ & $(-0.97)$ & $(-0.18)$ & $(-1.15)$ & $(-3.48)$ & {$[0.61]$} \\
\hline \multirow[t]{2}{*}{ New Zealand } & $0.031^{*}$ & -0.337 & -0.089 & -0.028 & -3.016 & 1.340 \\
\hline & $(3.08)$ & $(-1.01)$ & $(-0.59)$ & $(-1.11)$ & $(-4.81)$ & {$[0.51]$} \\
\hline \multirow[t]{2}{*}{ Norway } & $0.072^{*}$ & 0.009 & 0.190 & -0.067 & $-3.893^{*}$ & 0.745 \\
\hline & $(4.28)$ & $(0.04)$ & $(0.86)$ & $(-1.57)$ & $(-3.46)$ & {$[0.69]$} \\
\hline \multirow[t]{2}{*}{ Portugal } & $0.058^{*}$ & -0.080 & 0.335 & $-0.079^{*}$ & $-2.455^{*}$ & 2.455 \\
\hline & $(3.16)$ & $(-0.44)$ & $(1.49)$ & $(-2.10)$ & $(-11.11)$ & {$[0.29]$} \\
\hline Spain & 0.021 & -0.055 & 0.039 & $0.108^{*}$ & $-5.168^{*}$ & 0.107 \\
\hline & $(1.64)$ & $(-0.28)$ & $(0.17)$ & $(2.46)$ & $(-14.04)$ & {$[0.95]$} \\
\hline Sweden & $0.067^{*}$ & -0.249 & -0.025 & -0.021 & $-5.358^{*}$ & 0.700 \\
\hline & $(4.15)$ & $(-0.83)$ & $(-0.08)$ & $(-0.51)$ & $(-8.94)$ & {$[0.70]$} \\
\hline Switzerland & $0.040^{*}$ & -0.171 & 0.271 & $-0.087^{*}$ & $-6.788^{*}$ & 1.454 \\
\hline & $(3.84)$ & $(-0.58)$ & $(1.05)$ & $(-3.25)$ & $(-2.54)$ & {$[0.48]$} \\
\hline UK & $0.050^{*}$ & -0.254 & 0.104 & $-0.099^{*}$ & $-4.912^{*}$ & 1.859 \\
\hline & $(4.37)$ & $(-1.22)$ & $(0.59)$ & $(-3.45)$ & $(-2.69)$ & {$[0.39]$} \\
\hline US & $0.051^{*}$ & 0.016 & 0.048 & $-0.146^{*}$ & $-7.831^{*}$ & 0.140 \\
\hline & $(5.75)$ & $(0.12)$ & $(0.36)$ & $(-6.02)$ & $(-14.08)$ & {$[0.93]$} \\
\hline
\end{tabular}


Table IV. Regression of index returns on a month dummy and daylight saving time dummy: one hour increase or decrease

This table reports coefficient estimates from twenty-two country regressions of index returns on a constant, a DST Month dummy (corresponding to the month in which the DST changes typically take place) and a dummy for the Monday following a daylight saving time change: one hour increase or decrease (Spring or Fall). All indices are valueweighted, in domestic currency, including dividend distributions. We present parameter estimates (in percentages) with associated t-statistics in parentheses below, calculated using White's (1980) heteroskedasticity-robust standard errors. An asterisk denotes significance at the 5 percent level. For each regression, we report in the last column the $\chi^{2}$ realization and $\mathrm{p}$-value in square brackets for a $\chi 2$ test whether DST days (Spring and Fall) are different from all other trading days

\begin{tabular}{|c|c|c|c|c|c|c|}
\hline \multirow[b]{2}{*}{ Country } & \multirow[b]{2}{*}{ Const. } & \multicolumn{2}{|c|}{ DST change } & \multirow[b]{2}{*}{ Monday } & \multirow[b]{2}{*}{ Month } & \multirow{2}{*}{$\begin{array}{c}\text { Chi-Sq } \\
\text { [p-value] }\end{array}$} \\
\hline & & Spring & Fall & & & \\
\hline \multirow[t]{2}{*}{ Australia } & $0.043^{*}$ & -0.184 & 0.137 & $-0.042^{*}$ & -0.036 & 1.261 \\
\hline & $(5.23)$ & $(-0.74)$ & $(0.83)$ & $(-1.99)$ & $(-1.42)$ & {$[0.53]$} \\
\hline \multirow[t]{2}{*}{ Austria } & $0.018^{*}$ & -0.001 & 0.332 & 0.010 & $-0.031^{*}$ & 2.344 \\
\hline & $(2.35)$ & $(-0.01)$ & $(1.53)$ & $(0.53)$ & $(-1.71)$ & {$[0.31]$} \\
\hline \multirow[t]{2}{*}{ Belgium } & $0.046^{*}$ & -0.224 & 0.004 & $-0.074^{*}$ & -0.038 & 0.793 \\
\hline & $(3.35)$ & $(-0.82)$ & $(0.02)$ & $(-2.80)$ & $(-1.19)$ & {$[0.67]$} \\
\hline \multirow[t]{2}{*}{ Canada } & $0.054^{*}$ & -0.046 & -0.300 & $-0.072^{*}$ & -0.038 & 0.793 \\
\hline & $(4.93)$ & $(-0.35)$ & $(-0.82)$ & $(-2.71)$ & $(-1.19)$ & {$[0.67]$} \\
\hline \multirow[t]{2}{*}{ Denmark } & $0.056^{*}$ & 0.263 & 0.120 & $-0.072^{*}$ & -0.002 & 2.187 \\
\hline & $(4.84)$ & $(1.39)$ & $(0.51)$ & $(-2.71)$ & $(-0.05)$ & [0.33] \\
\hline \multirow[t]{2}{*}{ Finland } & 0.026 & -0.354 & -0.315 & -0.006 & 0.114 & 1.182 \\
\hline & $(0.86)$ & $(-0.86)$ & $(-0.68)$ & $(-0.09)$ & $(1.52)$ & {$[0.55]$} \\
\hline \multirow[t]{2}{*}{ France } & $0.038^{*}$ & 0.220 & -0.052 & -0.042 & 0.012 & 0.679 \\
\hline & $(2.89)$ & $(0.79)$ & $(-0.22)$ & $(-1.43)$ & $(0.37)$ & {$[0.71]$} \\
\hline \multirow{2}{*}{ Germany } & $0.031^{*}$ & -0.137 & 0.188 & -0.038 & 0.013 & 0.440 \\
\hline & $(2.65)$ & $(-0.46)$ & $(0.48)$ & $(-1.34)$ & $(0.43)$ & {$[0.80]$} \\
\hline \multirow[t]{2}{*}{ Greece } & $0.108^{*}$ & -0.237 & -0.061 & -0.123 & $-0.151^{*}$ & 0.389 \\
\hline & $(3.64)$ & $(-0.62)$ & $(-0.11)$ & $(-1.48)$ & $(-2.11)$ & {$[0.82]$} \\
\hline \multirow[t]{2}{*}{ Hong Kong } & $0.100^{*}$ & -0.162 & $1.148^{*}$ & $-0.201^{*}$ & -0.066 & 3.040 \\
\hline & $(4.47)$ & $(-0.27)$ & $(1.72)$ & $(-3.11)$ & $(-1.04)$ & {$[0.22]$} \\
\hline \multirow[t]{2}{*}{ Ireland } & $0.044^{*}$ & -0.240 & -0.765 & -0.017 & 0.015 & 2.572 \\
\hline & $(2.55)$ & $(-0.83)$ & $(-1.38)$ & $(-0.41)$ & $(0.31)$ & {$[0.28]$} \\
\hline \multirow[t]{2}{*}{ Italy } & $0.053^{*}$ & 0.022 & 0.151 & $-0.129^{*}$ & -0.012 & 0.547 \\
\hline & $(4.00)$ & $(0.10)$ & $(0.73)$ & $(-4.01)$ & $(-0.04)$ & {$[0.76]$} \\
\hline \multirow[t]{2}{*}{ Luxembourg } & $0.050^{*}$ & -0.007 & $-0.405^{*}$ & 0.005 & -0.022 & $10.676^{*}$ \\
\hline & $(3.45)$ & $(-0.05)$ & $(-3.26)$ & $(0.15)$ & $(-0.59)$ & {$[0.01]$} \\
\hline \multirow[t]{2}{*}{ Netherlands } & $0.044^{*}$ & -0.342 & -0.260 & -0.060 & 0.039 & 2.008 \\
\hline & $(2.71)$ & $(-1.01)$ & $(-1.01)$ & $(-1.46)$ & $(0.86)$ & {$[0.37]$} \\
\hline \multirow[t]{2}{*}{ New Zealand } & $0.033^{*}$ & -0.326 & -0.078 & -0.028 & -0.014 & 1.18 \\
\hline & $(3.26)$ & $(-0.98)$ & $(-0.51)$ & $(-1.12)$ & $(-0.50)$ & {$[0.55]$} \\
\hline \multirow{2}{*}{ Norway } & $0.074^{*}$ & 0.021 & 0.023 & $-0.074^{*}$ & -0.012 & 0.017 \\
\hline & $(4.23)$ & $(0.09)$ & $(0.10)$ & $(-1.71)$ & $(-0.23)$ & [0.99] \\
\hline \multirow[t]{2}{*}{ Portugal } & $0.061^{*}$ & -0.066 & 0.206 & $-0.082^{*}$ & -0.018 & 0.837 \\
\hline & $(2.99)$ & $(-0.36)$ & $(0.83)$ & $(-2.15)$ & $(-0.40)$ & {$[0.66]$} \\
\hline Spain & $0.027^{*}$ & -0.031 & -0.113 & $0.096^{*}$ & -0.032 & 0.195 \\
\hline & $(1.98)$ & $(-0.16)$ & $(-0.41)$ & $(2.16)$ & $(-0.87)$ & {$[0.91]$} \\
\hline Sweden & $0.069^{*}$ & -0.237 & -0.227 & -0.030 & -0.009 & 1.001 \\
\hline & $(3.98)$ & $(-0.79)$ & $(-0.62)$ & $(-0.73)$ & $(-0.19)$ & {$[0.61]$} \\
\hline Switzerland & $0.035^{*}$ & -0.178 & -0.009 & $-0.094^{*}$ & 0.023 & 0.367 \\
\hline & $(3.17)$ & $(-0.61)$ & $(-0.04)$ & $(-3.41)$ & $(0.80)$ & [0.83] \\
\hline UK & $0.053^{*}$ & -0.239 & -0.170 & $-0.103^{*}$ & -0.017 & 1.741 \\
\hline & $(4.37)$ & $(-1.14)$ & $(-0.68)$ & $(-3.53)$ & $(-0.55)$ & {$[0.42]$} \\
\hline US & $0.052^{*}$ & -0.010 & -0.397 & $-0.121^{*}$ & 0.021 & 1.691 \\
\hline & $(6.36)$ & $(-0.07)$ & $(-1.30)$ & $(-5.90)$ & $(1.01)$ & {$[0.43]$} \\
\hline
\end{tabular}




\section{Appendix 1 - "Replicating" KKL - Date Differences from KKL}

For the US, UK and Germany, KKL's dates for DST changes differ slightly from ours. While we do not believe these differences are a significant explanation for our contrasting conclusions, they may explain some of the apparent discrepancies.

For the USA, KKL note:

In the United States and Canada, until 1986, the Spring time change always occurred on the last Sunday in April. As of 1987, the Spring time change takes place on the first Sunday in April. The Fall time change has always occurred on the last Sunday in October. There were no time changes during World War II or in the year 1974; clocks were kept ahead in both periods to conserve energy. ${ }^{19}$

While we agree there was a Spring change in January 1974 (implied by the wording of that last sentence), we also record a Fall DST event in 1974 (which KKL does not), and an earlier than usual Spring DST change in February 1975. We use a more recent Shanks source than KKL (2003 vs. 1985), and we have cross-checked our dates with several relevant internet sites (e.g., www.timeanddate.com) as well as an online version of the Doane source KKL cite. We believe our data to be correct.

For the UK, regarding the Fall DST change, KKL state:

The Fall daylight saving change in the United Kingdom was on October 31 in 1971, on the fourth Sunday in October from 1972 to 1984, and on the last Sunday in October from 1985 onward. ${ }^{20}$

KKL's source is Shanks (1985), so they may have missed changes to post-1985 DST dates. Our date differences seem to stem from the difference between the fourth and last Sunday of October. Obviously, this only matters in months that have five Sundays. From 1985 to 1999 (the end of KKL's data sample), October had five Sundays in the years 1988, 1989, 1993-1995 and 1999. While we did not use an algorithm, our dates conform to a "4th Sunday" rule for all of those years except 1989, where it is the last (5th) Sunday.

\footnotetext{
${ }^{19}$ KKL, pp. 1006-7.

${ }^{20}$ KKL, p. 1007.
} 
Although this may seem unusual, so have many other DST date changes that have occurred over the years. We have cross-checked the dates from Shanks and Pottenger (2003) with several online sources, and believe it to be correct.

For Germany, from KKL:

In 1980 the Spring change occurred on May 5 and on the last Sunday in March from 1981

onward, whereas the Fall change took place on the last Sunday in September from 1980 onward. $^{21}$

Shanks and Pottenger (2003) show the 1980 Spring DST change occurring on April 6 rather than May 5. This is confirmed with several other sources, and is the same as the 1980 Spring change for all other European countries except the UK (which was in March that year).

The final difference begins in 1996. In that year, Germany changed, along with the rest of Europe, to a "last Sunday in October" rule for the Fall change. Therefore, we have DST Fall changes in October for 1996-1999 rather than in September as stated by KKL. Again, we believe this is due to KKL using outdated source material. ${ }^{22}$

\section{Results comparison with KKL on same dates}

As the difference in our results for the four countries that KKL examine could be caused either by the different sample period or different dates, we run regressions on the same years as KKL, using KKL's version of the dates (with and without error correction), as well as our version of the dates.

In Panel A of Table A1 are our results which should most resemble KKL's results - the years their study spans, their DST dates and no error correction (and no correction for the

\footnotetext{
${ }^{21}$ KKL, p. 1007.

${ }^{22}$ We could have the same problem. Our source is dated 2003, and our sample period runs through 2005 (in fact New Zealand revised DST dates in 2006, and the USA did so in 2007). However, we have checked with online sources, and believe there were no modifications to DST dates in 2004 or 2005 for our sample of countries.
} 
1987 and 1997 outliers). We find here, as do they, significantly negative results in Canada, UK and USA.

\section{Please insert Table Al around here.}

In Panel B, contrary to a footnote in KKL, we find that after using White error correction, the significant results disappear, except for the Spring change in the UK. Finally, in Panel $\mathrm{C}$, using the DST dates that we identified and with error correction, the DST effect vanishes at the 5\% level, though the USA Fall change is just significant at the $10 \%$ level. 


\section{Table A1, "Replicating" KKL}

This table reports coefficient estimates for the four countries used in KKL. DST dates are those defined by KKL for panels $\mathrm{a}$ and $\mathrm{b}$ while using our date definitions in panel $\mathrm{c}$. Regressions are index returns on a constant and a dummy for the trading day following the weekend of a daylight saving time change: one hour increase for the Spring change or decrease for the Fall change. All indices are value-weighted, in domestic currency, including dividend distributions. We present parameter estimates (in percentages) with associated t-statistics in parentheses below, calculated with and without White's (1980) heteroskedasticity-robust standard errors. An asterisk denotes significance at the 5 percent level.

\begin{tabular}{lccc} 
Panel A: KKL DST dates \\
$\begin{array}{l}\text { Country/ } \\
\text { Period }\end{array}$ & Const. & $\begin{array}{c}\text { DST change } \\
\text { Spring }\end{array}$ & $\begin{array}{c}\text { DST change } \\
\text { Fall }\end{array}$ \\
\hline Canada & 0.035 & -0.209 & $-0.419^{*}$ \\
$1969-1998$ & $(3.46)$ & $(-1.29)$ & $(-2.60)$ \\
\hline Germany & 0.026 & -0.13 & -0.234 \\
$1973-1998$ & $(2.19)$ & $(-0.55)$ & $(-0.14)$ \\
\hline UK & 0.039 & $-0.427^{*}$ & $-0.467^{*}$ \\
$1969-1998$ & $(3.36)$ & $(-2.20)$ & $(-2.46)$ \\
\hline USA & 0.024 & -0.153 & $-0.593^{*}$ \\
$1967-1997$ & $(2.76)$ & $(-0.72)$ & $(-2.79)$ \\
\hline
\end{tabular}

Panel B: KKL DST dates; White standard errors

\begin{tabular}{lccc}
\hline $\begin{array}{l}\text { Country/ } \\
\text { Period }\end{array}$ & Const. & $\begin{array}{c}\text { DST change } \\
\text { Spring }\end{array}$ & $\begin{array}{c}\text { DST change } \\
\text { Fall }\end{array}$ \\
\hline Canada & 0.035 & -0.209 & -0.419 \\
$1969-1998$ & $(3.49)$ & $(-1.59)$ & $(-0.92)$ \\
\hline Germany & 0.026 & -0.13 & -0.234 \\
$1973-1998$ & $(2.20)$ & $(-0.43)$ & $(-0.08)$ \\
\hline UK & 0.039 & $-0.427^{*}$ & -0.467 \\
$1969-1998$ & $(3.38)$ & $(-2.36)$ & $(-1.47)$ \\
\hline USA & 0.024 & -0.153 & -0.593 \\
$1967-1997$ & $(2.76)$ & $(-1.07)$ & $(-1.58)$ \\
\hline
\end{tabular}

Panel C: Our DST dates, White standard errors

\begin{tabular}{lccc}
\hline $\begin{array}{l}\text { Country/ } \\
\text { Period }\end{array}$ & Const. & $\begin{array}{c}\text { DST change } \\
\text { Spring }\end{array}$ & $\begin{array}{c}\text { DST change } \\
\text { Fall }\end{array}$ \\
\hline Canada & 0.034 & -0.100 & -0.386 \\
$1969-1998$ & $(3.54)$ & $(-0.78)$ & $(-1.06)$ \\
\hline Germany & 0.025 & -0.134 & 0.210 \\
$1973-1998$ & $(2.51)$ & $(-0.46)$ & $(0.59)$ \\
\hline UK & 0.032 & -0.282 & -0.351 \\
$1969-1998$ & $(3.00)$ & $(-1.46)$ & $(-1.28)$ \\
\hline USA & 0.022 & -0.056 & -0.541 \\
$1967-1997$ & $(2.69)$ & $(-0.42)$ & $(-1.71)$ \\
\hline
\end{tabular}




\section{Appendix 2 - DST dates list}

Table A2. DST dates for which we have return data

We use the following notation: S means DST Spring change; F means DST Fall change. Only nationally standardized DST changes are recorded. All DST changes occur early Sunday morning (or late Saturday night), except * Monday.

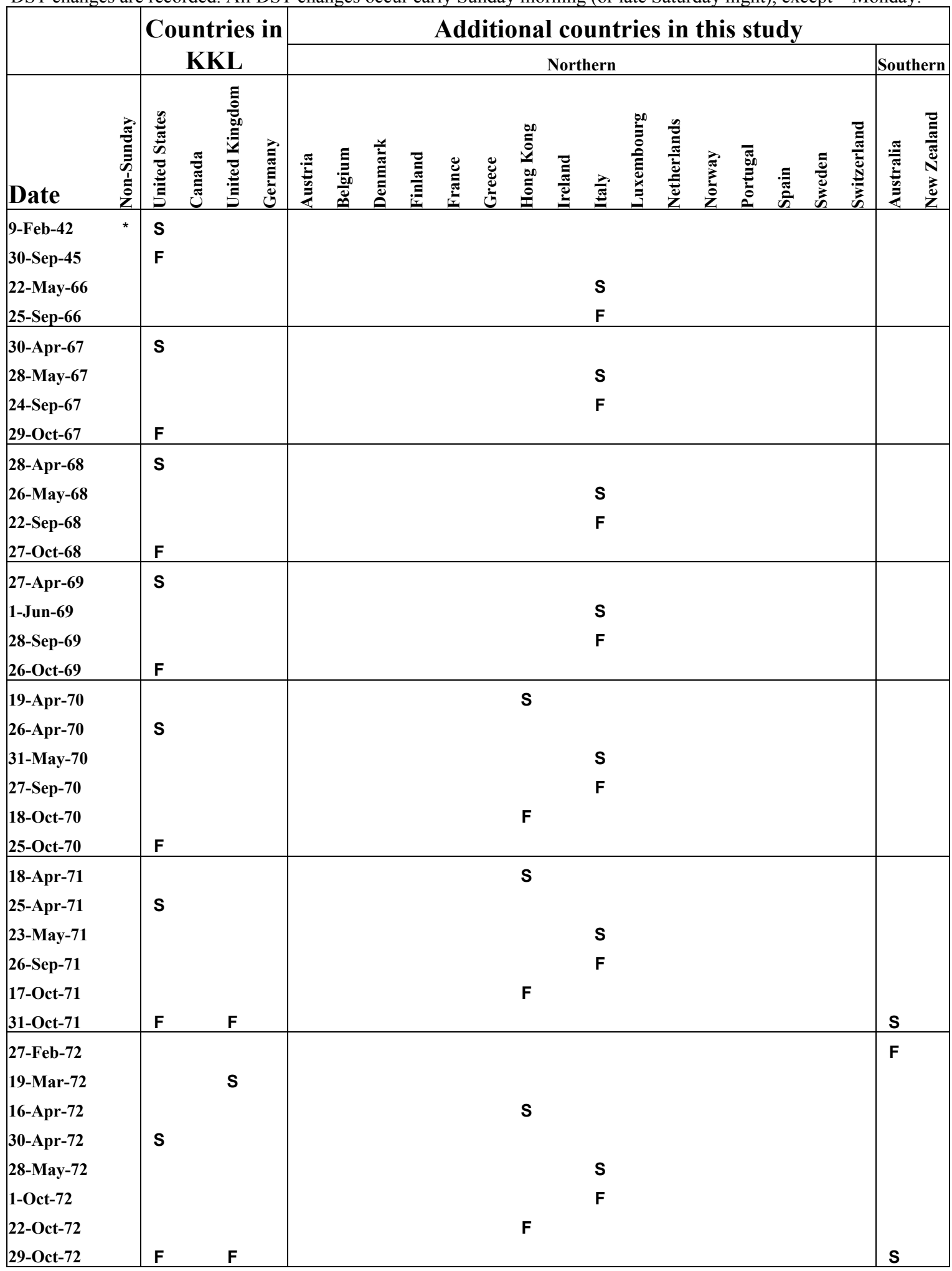


Table A2. DST dates - continued

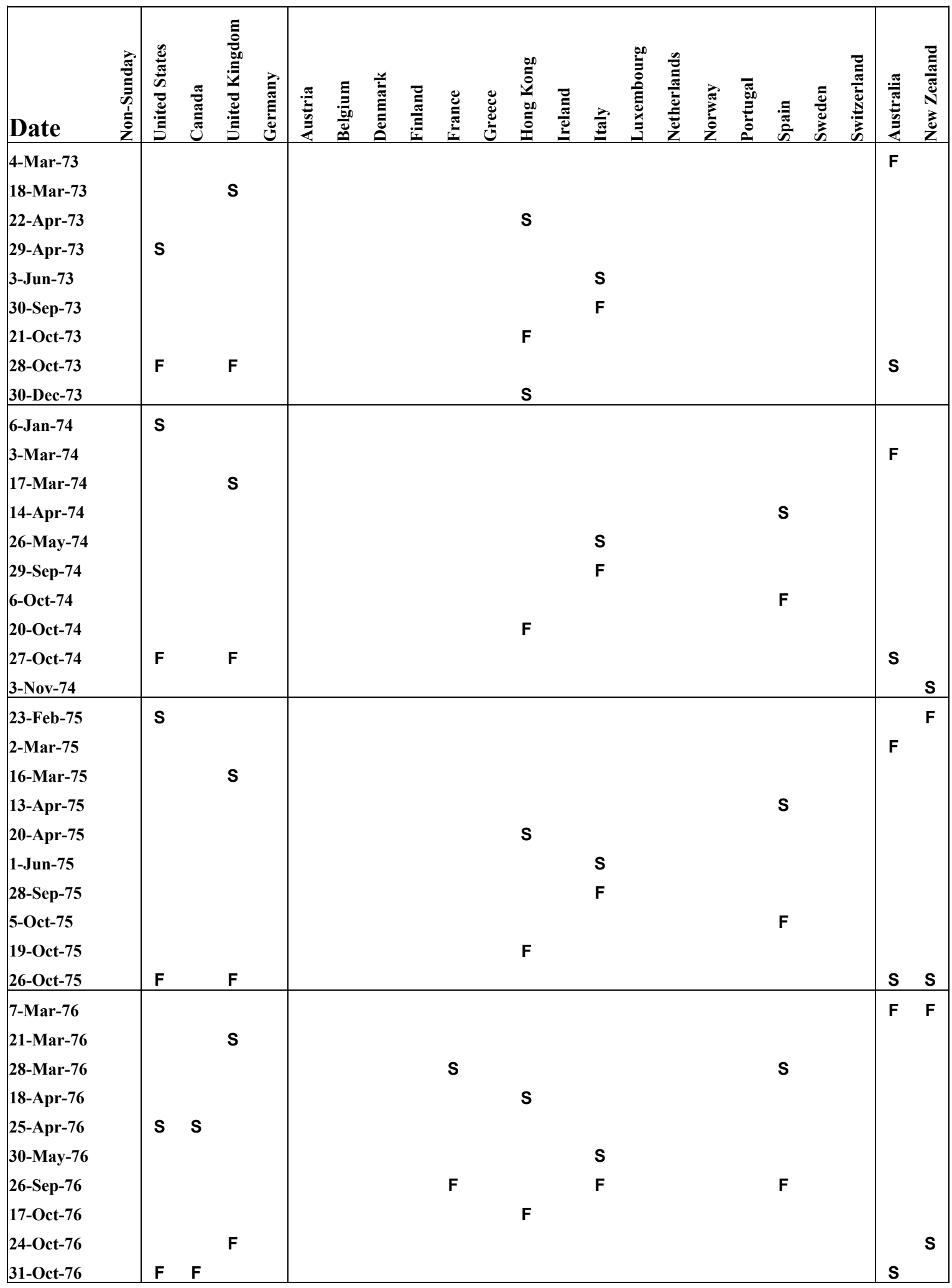


Table A2. DST dates - continued

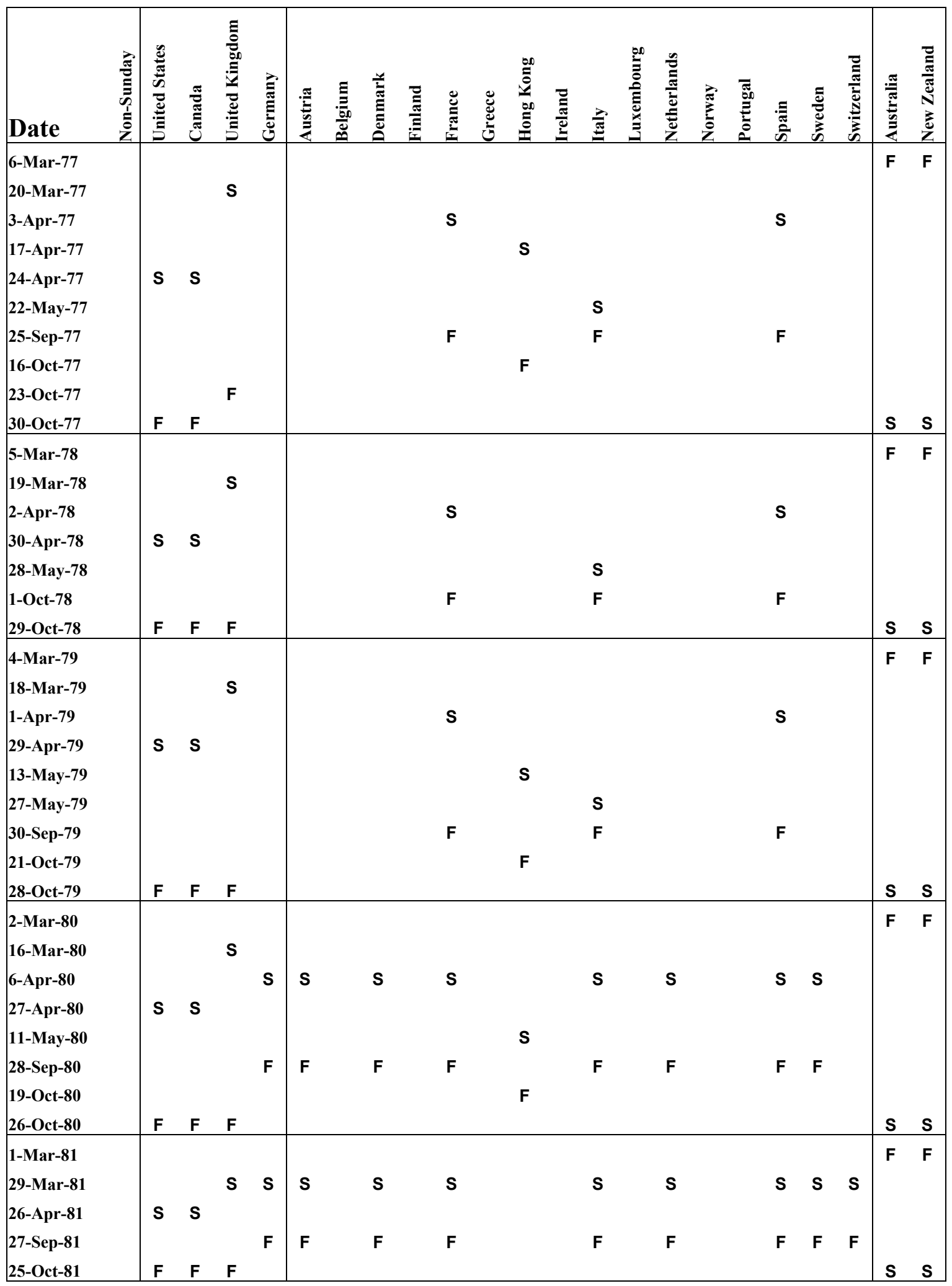


Table A2. DST dates - continued

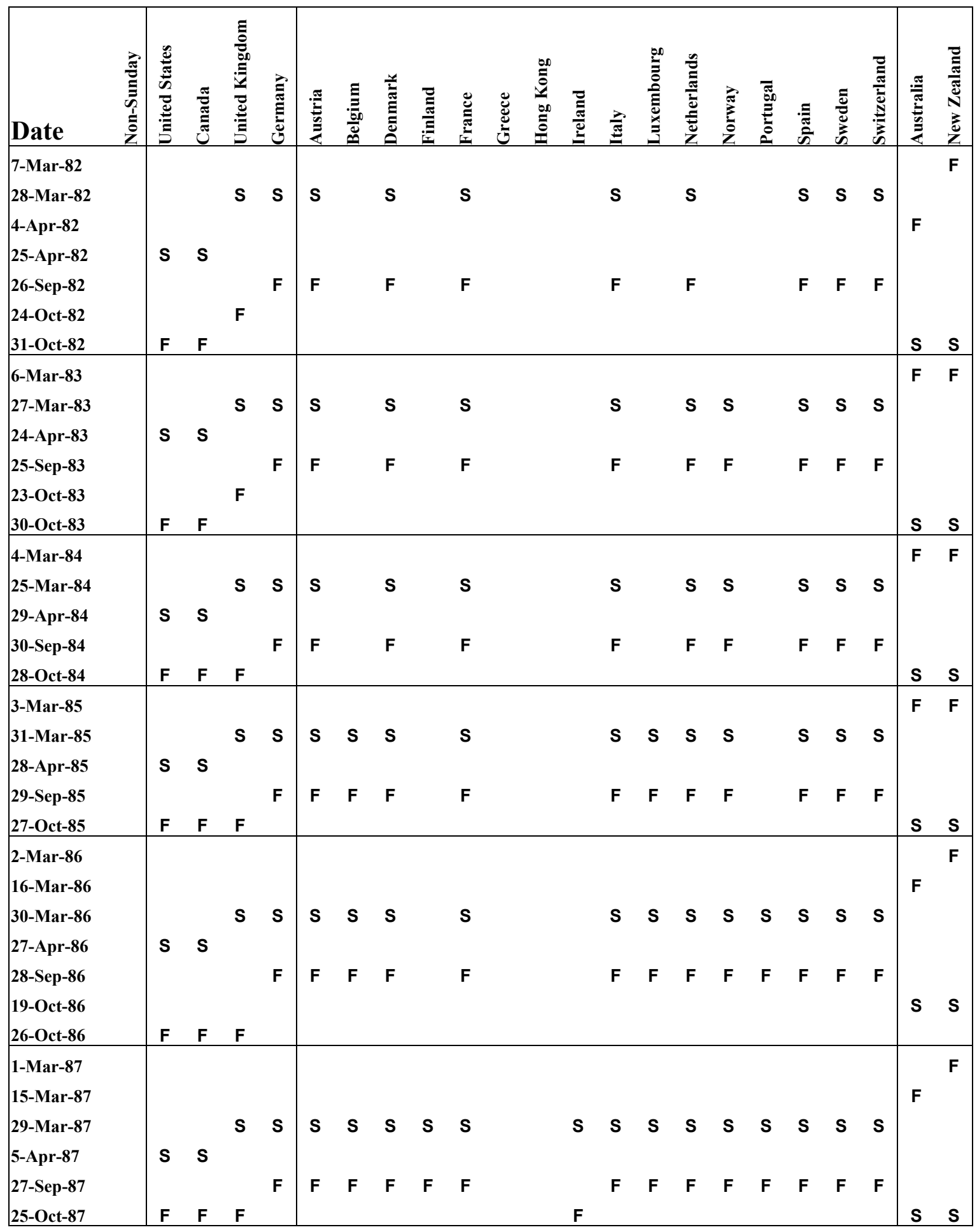


Table A2. DST dates - continued

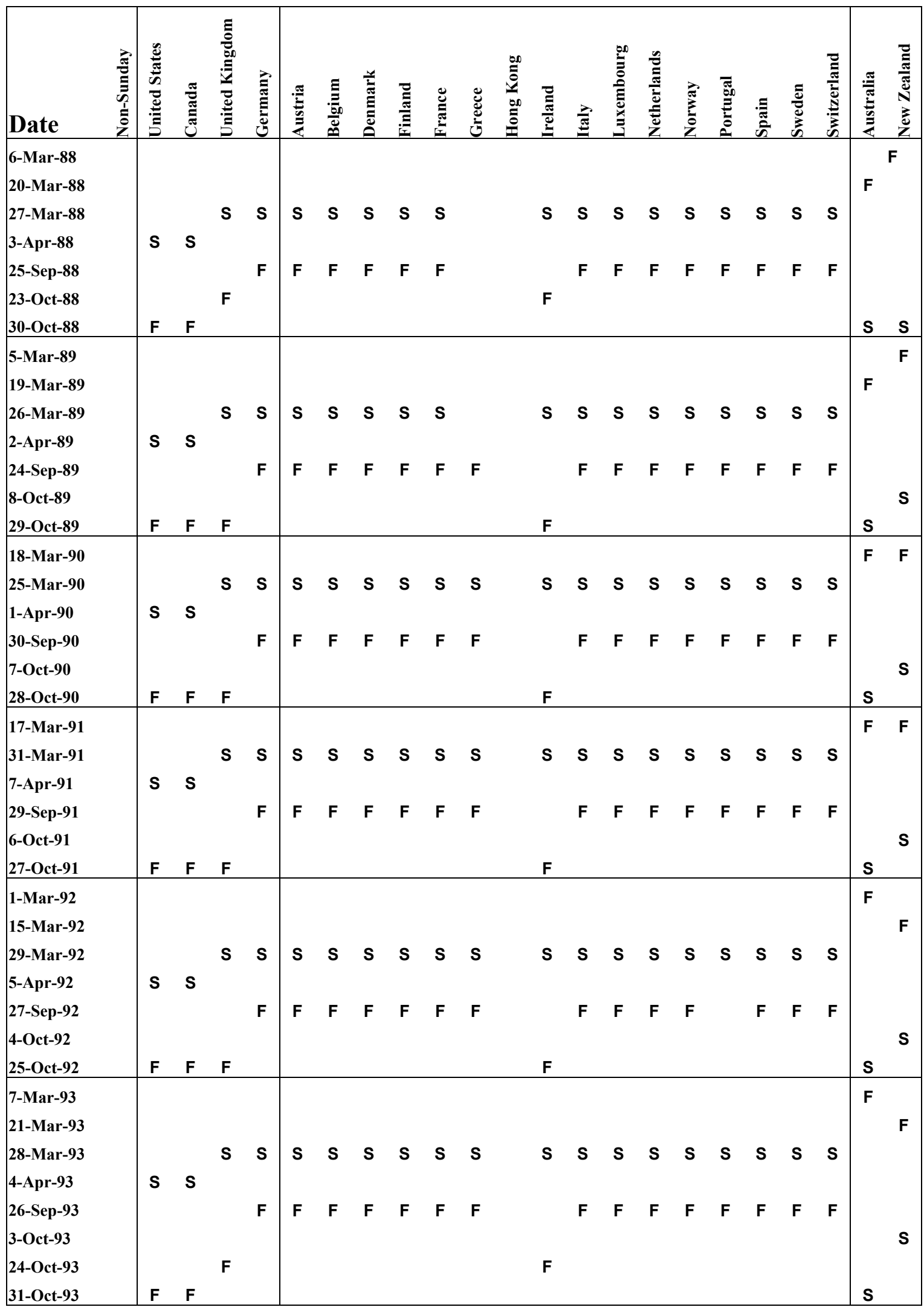


Table A2. DST dates - continued

\begin{tabular}{|c|c|c|c|c|c|c|c|c|c|c|c|c|c|c|c|c|c|c|c|c|c|c|c|}
\hline Date & 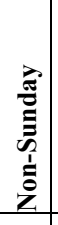 & 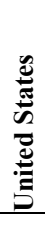 & Uٓ & 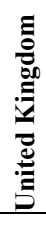 & 离 & 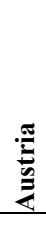 & 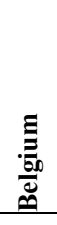 & 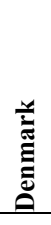 & 总 & 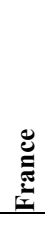 & 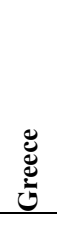 & $\begin{array}{l}00 \\
\overline{0} \\
0 \\
00 \\
\overline{0} \\
0\end{array}$ & 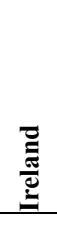 & 齐 & 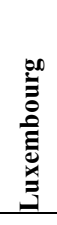 & 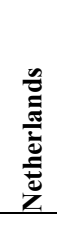 & Żं & 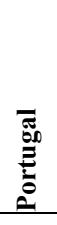 & 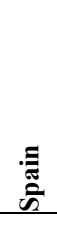 & $\begin{array}{l}0 \\
\frac{0}{0} \\
0 \\
0\end{array}$ & 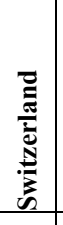 & 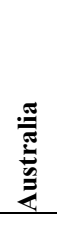 & 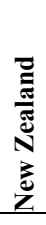 \\
\hline 6-Mar-94 & & & & & & & & & & & & & & & & & & & & & & $F$ & \\
\hline 20-Mar-94 & & & & & & & & & & & & & & & & & & & & & & & $\mathbf{F}$ \\
\hline 27-Mar-94 & & & & S & S & $\mathbf{S}$ & $\mathbf{S}$ & $\mathbf{S}$ & $\mathbf{s}$ & $\mathbf{S}$ & $\mathbf{S}$ & & $\mathbf{S}$ & $\mathbf{S}$ & s & s & S & $\mathbf{S}$ & S & S & $\mathbf{S}$ & & \\
\hline 3-Apr-94 & & s & $\mathbf{S}$ & & & & & & & & & & & & & & & & & & & & \\
\hline 25-Sep-94 & & & & & $\mathbf{F}$ & $\mathbf{F}$ & $\mathbf{F}$ & $\mathbf{F}$ & $\mathbf{F}$ & $\mathbf{F}$ & $\mathbf{F}$ & & & $\mathbf{F}$ & $\mathbf{F}$ & $F$ & $\mathbf{F}$ & $F$ & $F$ & $F$ & $F$ & & \\
\hline 2-Oct-94 & & & & & & & & & & & & & & & & & & & & & & & S \\
\hline 23-Oct-94 & & & & $F$ & & & & & & & & & $\mathbf{F}$ & & & & & & & & & & \\
\hline 30-Oct-94 & & $\mathbf{F}$ & $\mathbf{F}$ & & & & & & & & & & & & & & & & & & & S & \\
\hline 5-Mar-95 & & & & & & & & & & & & & & & & & & & & & & $\mathbf{F}$ & \\
\hline 19-Mar-95 & & & & & & & & & & & & & & & & & & & & & & & $F$ \\
\hline 26-Mar-95 & & & & S & S & S & $\mathbf{S}$ & $\mathbf{s}$ & $\mathbf{s}$ & $\mathbf{S}$ & $\mathbf{S}$ & & $\mathbf{s}$ & $\mathbf{S}$ & s & $\mathbf{S}$ & s & S & s & s & s & & \\
\hline 2-Apr-95 & & S & $\mathbf{S}$ & & & & & & & & & & & & & & & & & & & & \\
\hline 24-Sep-95 & & & & & $\mathbf{F}$ & $\mathbf{F}$ & $\mathbf{F}$ & $\mathbf{F}$ & $\mathbf{F}$ & $\mathbf{F}$ & $\mathbf{F}$ & & & $\mathbf{F}$ & $\mathbf{F}$ & $\mathbf{F}$ & $\mathbf{F}$ & $F$ & $F$ & $F$ & $\mathbf{F}$ & & \\
\hline 1-Oct-95 & & & & & & & & & & & & & & & & & & & & & & & S \\
\hline 22-Oct-95 & & & & $F$ & & & & & & & & & $F$ & & & & & & & & & & \\
\hline 29-Oct-95 & & $\mathbf{F}$ & $\mathbf{F}$ & & & & & & & & & & & & & & & & & & & $\mathbf{S}$ & \\
\hline 17-Mar-96 & & & & & & & & & & & & & & & & & & & & & & & $\mathbf{F}$ \\
\hline 31-Mar-96 & & & & S & S & S & $\mathbf{S}$ & $\mathbf{S}$ & $\mathbf{S}$ & $\mathbf{S}$ & $\mathbf{S}$ & & $\mathbf{S}$ & $\mathbf{S}$ & $\mathbf{S}$ & S & S & S & s & S & S & $\mathbf{F}$ & \\
\hline 7-Apr-96 & & S & $\mathbf{S}$ & & & & & & & & & & & & & & & & & & & & \\
\hline 6-Oct-96 & & & & & & & & & & & & & & & & & & & & & & & S \\
\hline 27-Oct-96 & & $\mathbf{F}$ & $\mathbf{F}$ & $\mathbf{F}$ & $\mathbf{F}$ & $\mathbf{F}$ & $\mathbf{F}$ & $\mathbf{F}$ & $\mathbf{F}$ & $\mathbf{F}$ & $\mathbf{F}$ & & $\mathbf{F}$ & $\mathbf{F}$ & $\mathbf{F}$ & $\mathbf{F}$ & $\mathbf{F}$ & $\mathbf{F}$ & $\mathbf{F}$ & $\mathbf{F}$ & $\mathbf{F}$ & $S$ & \\
\hline 16-Mar-97 & & & & & & & & & & & & & & & & & & & & & & & $\mathbf{F}$ \\
\hline 30-Mar-97 & & & & S & S & $\mathbf{S}$ & $\mathbf{S}$ & $\mathbf{S}$ & $\mathbf{s}$ & $\mathbf{S}$ & $\mathbf{S}$ & & $\mathbf{S}$ & $\mathbf{S}$ & $\mathbf{s}$ & $\mathbf{S}$ & s & $\mathbf{S}$ & $\mathbf{s}$ & S & S & $F$ & \\
\hline 6-Apr-97 & & S & $\mathbf{s}$ & & & & & & & & & & & & & & & & & & & & \\
\hline 5-Oct-97 & & & & & & & & & & & & & & & & & & & & & & & S \\
\hline 26-Oct-97 & & $\mathbf{F}$ & $\mathbf{F}$ & $\mathbf{F}$ & $\mathbf{F}$ & $\mathbf{F}$ & $\mathbf{F}$ & $\mathbf{F}$ & $\mathbf{F}$ & $\mathbf{F}$ & $\mathbf{F}$ & & $\mathbf{F}$ & $\mathbf{F}$ & $\mathbf{F}$ & $\mathbf{F}$ & $\mathbf{F}$ & $\mathbf{F}$ & $\mathbf{F}$ & $\mathbf{F}$ & $\mathbf{F}$ & $\mathbf{S}$ & \\
\hline 15-Mar-98 & & & & & & & & & & & & & & & & & & & & & & & $\mathbf{F}$ \\
\hline 29-Mar-98 & & & & S & S & $\mathbf{S}$ & $\mathbf{S}$ & $\mathbf{S}$ & s & $\mathbf{S}$ & $\mathbf{S}$ & & $\mathbf{S}$ & $\mathbf{S}$ & $\mathbf{S}$ & $S$ & 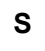 & $S$ & $s$ & s & S & $F$ & \\
\hline 5-Apr-98 & & S & $\mathbf{S}$ & & & & & & & & & & & & & & & & & & & & \\
\hline 4-Oct-98 & & & & & & & & & & & & & & & & & & & & & & & $\mathbf{S}$ \\
\hline 25-Oct-98 & & $\mathbf{F}$ & $\mathbf{F}$ & $\mathbf{F}$ & $\mathbf{F}$ & $\mathbf{F}$ & $\mathbf{F}$ & $\mathbf{F}$ & $\mathbf{F}$ & $\mathbf{F}$ & $\mathbf{F}$ & & $\mathbf{F}$ & $\mathbf{F}$ & $\mathbf{F}$ & $\mathbf{F}$ & $\mathbf{F}$ & $\mathbf{F}$ & $\mathbf{F}$ & $\mathbf{F}$ & $\mathbf{F}$ & $\mathbf{S}$ & \\
\hline 21-Mar-99 & & & & & & & & & & & & & & & & & & & & & & & $\mathbf{F}$ \\
\hline 28-Mar-99 & & & & s & s & s & $\mathbf{S}$ & $S$ & s & $\mathbf{S}$ & $\mathbf{S}$ & & $\mathbf{S}$ & $\mathbf{S}$ & $\mathbf{S}$ & $\mathbf{S}$ & s & $\mathbf{S}$ & $\mathbf{S}$ & S & S & $\mathbf{F}$ & \\
\hline 4-Apr-99 & & S & $\mathbf{S}$ & & & & & & & & & & & & & & & & & & & & \\
\hline 3-Oct-99 & & & & & & & & & & & & & & & & & & & & & & & $S$ \\
\hline 31-Oct-99 & & $\mathbf{F}$ & $\mathbf{F}$ & $\mathbf{F}$ & $\mathbf{F}$ & $\mathbf{F}$ & $\mathbf{F}$ & $\mathbf{F}$ & $\mathbf{F}$ & $\mathbf{F}$ & $\mathbf{F}$ & & $\mathbf{F}$ & $\mathbf{F}$ & $\mathbf{F}$ & $\mathbf{F}$ & $\mathbf{F}$ & $\mathbf{F}$ & $\mathbf{F}$ & $\mathbf{F}$ & $\mathbf{F}$ & $\mathbf{S}$ & \\
\hline
\end{tabular}


Table A2. DST dates - continued

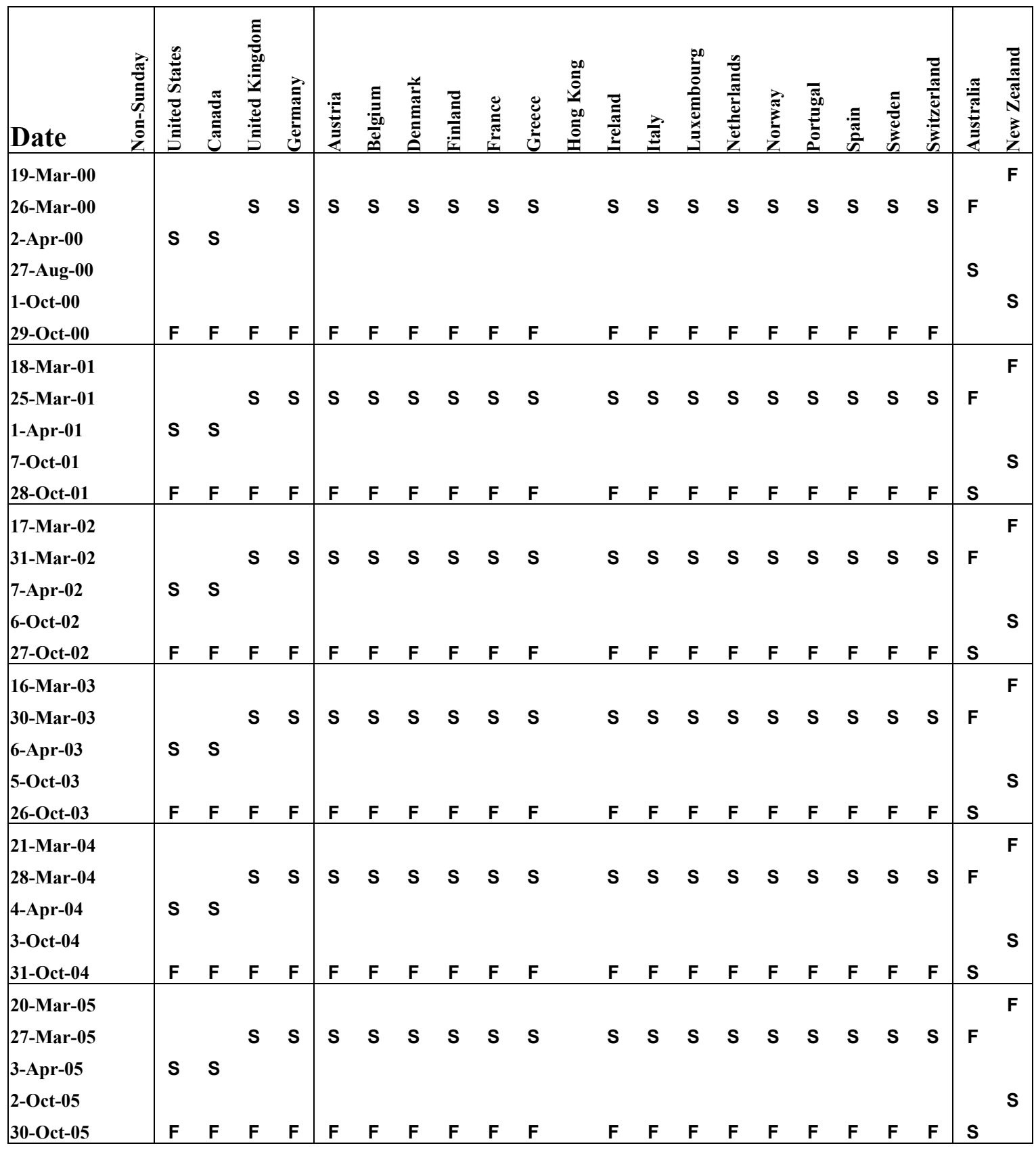

